\title{
Guidance in computer-supported collaborative inquiry learning: Capturing aspects of affect and teacher support in science classrooms
}

\author{
Tarja Pietarinen $^{1}$ (D) Tuire Palonen ${ }^{1} \cdot$ Marja Vauras $^{1}$
}

Received: 26 January 2021 / Accepted: 22 May 2021 / Published online: 15 June 2021

(c) The Author(s) 2021

\begin{abstract}
Technology-enhanced collaborative inquiry learning has gained a firm position in curricula across disciplines and educational settings and has become particularly pervasive in science classrooms. However, understanding of the teacher's role in this context is limited. This study addresses the real-time shifts in focus and distribution of teachers' guidance and support of different student groups during in-person computer-supported collaborative inquiry learning in science classrooms. Teachers' self-perceptions of their guidance and affect were supplemented with students' self-reported affect. A mixed-methods approach using video analyses and questionnaire data revealed differences between teacher guidance and support associated with teacher perceptions and group outcomes. Groups' prior science competence was not found to have an effect on teacher guidance and support, rather the teachers guided the groups they perceived as motivated and willing to collaborate. Teacher affect was compounded by student affect, suggesting that consideration of the reciprocal perceptions of teachers and students is necessary in order to understand the teachers' role in collaborative learning.
\end{abstract}

Keywords Teacher support - Small group collaboration · Science inquiry · Technology · Affect $\cdot$ Social network analysis

\section{Introduction}

In the transition from traditional teacher-centered teaching and learning to more autonomous constructivist learning-centered practices, inquiry learning has been a method frequently applied in science education (McNeill et al., 2013). From an educational

Tarja Pietarinen

tarja.pietarinen@utu.fi

Tuire Palonen

tuipalo@utu.fi

Marja Vauras

vauras@utu.fi

1 Department of Teacher Education \& Centre for Learning Research, University of Turku, 20014 Turku, Finland 
perspective, it is essential to distinguish between scientific inquiry (e.g., Lederman et al., 2019) and inquiry learning and teaching. Scientific inquiry uses empirical findings to explain phenomena in the natural world, whereas inquiry learning and teaching refers to a learning process in which students solve complex problems, providing reasoning and explanation. The teacher's role is to act as a coach and facilitator of students' thinking while modeling the learning process (Anderson, 2002). Modern technology has enabled actual inquiry to be a crucial part of inquiry learning and teaching, but its rapid development and adoption in education have increased the need for students to develop new skills and competencies (Ananiadou \& Claro, 2009; Care et al., 2018). This further suggests the need to reinterpret the current competencies of teachers as well.

Empirical findings show that integrating technology with inquiry instruction can help teachers to engage their students in experimental investigations, especially in secondary science classrooms (Maeng et al., 2013). However, technological tools, such as virtual learning environments (VLEs), cannot assist student learning entirely on their own; teachers are also crucial in supporting students' technology enhanced learning (Dillenbourg \& Jermann, 2010). The importance of teacher-student interactive talk and support in scientific reasoning and knowledge building is emphasized in all science learning. Expert teachers establish science understanding by eliciting and acknowledging student responses and by clarifying and extending student ideas (Tytler \& Aranda, 2015). Challenges arise when teachers must calibrate their support with the specific features of the technological tools in use (e.g., to compensate for a learning application's provision of tasks, materials, and builtin learning supports). As Harris and Rooks (2010) emphasize, teachers need to manage the interdependency between science ideas, instructional materials, tasks, and students, and the overall social context in order to support and sustain learning.

Science, as a demanding domain, involves complex and challenging learning tasks that can be beyond individual attainment and require group work. Thus, collaborative activities in scientific inquiry learning are widely recommended, and evidence shows that collaborative work in small groups is positively associated with student achievement in high school science (Kirschner et al., 2011). However, it can be further claimed that simply offering students the opportunity to work in a group context is not sufficient to support high-level science learning (Sampson \& Clark, 2009; Vauras et al., 2019; Volet et al., 2013). Inquiry-based methods involving collaboration and enriched technology, which today are typical in science learning, fail without adequate teacher guidance to provide sufficient support for learning demanding scientific concepts and procedures (Hmelo-Silver et al., 2007; Kirschner et al., 2006; Vauras et al., 2019). Teachers' adaptive expertise (see Darling-Hammond \& Bransford, 2006) is required to know how and when to intervene in students' collaborative work without shortcircuiting their disciplinary thinking (Nolen et al., 2020).

Despite a large body of literature on teacher practices and support in traditional classrooms, understanding how teachers implement their expertise in novel, technologyenhanced collaborative learning environments remains limited. The present study extends our understanding of science teachers' guidance and support of computer-supported collaborative learning (CSCL) in high school science when students are engaged in virtual experimentation concerning ocean acidification. The study focuses on teacher activity, teachers' self-perception of their own guidance and affect, and student-reported affect, thus contributing to the sparse body of knowledge on the intertwined connections of teacher guidance and support, affect, and productive learning outcomes. Teachers' support and affect can be considered as crucial components for successful science learning, as a supportive environment may foster not only students' content understanding but also the task value and their positive beliefs in their own abilities. Positive beliefs and teacher support 
seem to directly impact students' motivation to engage in learning (Zhang et al., 2012). Further, it is also shown that teachers' affect impacts their own teaching approach, instructional behavior, and students' affect (Becker et al., 2014; Trigwell, 2012).

The purpose and importance of this study will be argued through a review of relevant literature underlying the study. First, findings from research on teacher guidance and support related to inquiry learning and CSCL will be introduced. Second, findings from relevant research on teacher efficacy, beliefs and affect will be reviewed together in connection with student affect in inquiry learning.

\section{Teacher guidance and support in technology-enhanced collaborative inquiry learning}

Inquiry learning is a typical method used in problem-solving activities in science learning (Spronken-Smith \& Walker, 2010). It refers to engagement in an active learning process where students develop knowledge and understanding of scientific ideas and the way scientists study the natural world. However, inquiry learning, scientific inquiry, and inquiry teaching are deeply intertwined (as is the case in the present study). Teachers' understanding of the nature of inquiry determines the orientation of science learning (Anderson, 2002). Consequently, there is a wide range of instructional practices for applying inquiry, as teachers may have limited views of inquiry-based instruction and the nature of science, and these views may be reflected in their teaching practices (Capps \& Crawford, 2013; Tseng et al., 2013).

Teachers may understand the importance of inquiry but may still lack knowledge and strategies for implementation (DiBiase \& McDonald, 2015). Teachers also consider their role as less important to inquiry learning than the students' inquiry process itself (Tseng et al., 2013). Yet, according to a meta-analysis by Furtak et al. (2012), inquiry lessons that are actively guided by teachers have a greater impact on student learning than those that are student-led. Students, in comparison, emphasize the balance between student autonomy and teacher guidance (Hijzen et al., 2007).

Learning in technology-enhanced collaborative inquiry requires instructional support in order to obtain all its benefits, as collaborating students bring different skills and abilities to their work, and there can be problems in group formation, group dynamics, and the learning process itself (Kreijns et al., 2013). At best, given the common goal, successful regulation of the group's processes (Järvenoja et al., 2020; Volet et al., 2013) enhances students' ability to gain subject knowledge, develop group skills, and further group cohesion, and, consequently, impacts students' satisfaction with collaborative learning (Dewiyanti et al., 2007).

Successful and unsuccessful collaborative groups have been shown to have different collaboration patterns and problem-solving strategies. While successful groups use more analytical reasoning processes, re-examination, topic-related questioning, and evidence-based scientific argumentation, unsuccessful groups more often apply a trial-anderror strategy to solve problems without systematic reexamination and argumentation (Chang et al., 2017; Telenius et al., 2020). Further, the acts of expressing disagreement, proposing ideas, and explaining reasoning often predict group members' knowledge gains (Howe et al., 2007) and thus create learning opportunities. These differences are in line with effective groups' emphasis on mastery goals and social responsibility, whereas ineffective groups seem to prefer entertainment and belongingness (Hijzen et al., 2007). This is supported by recent studies in which successful groups self-reported immersion 
in scientific reasoning and meaning-making and perceived motivation, support, and sharing in the group (Pietarinen et al., 2019; Vauras et al., 2019). Based on this evidence, guiding students in structuring problem-solving actions to create a shared understanding is crucial (Chang et al., 2017).

Observing student groups and their progress is particularly important. One study (Chiu, 2004) found that teacher interventions in small groups resulted in on-task conversations and new problem-solving solutions. Conversely, confusion about the procedure led to offtask discussions and continuous trial-and-error attempts. Most of the students did not ask the teacher for help at all. These results emphasize the role of the teacher in identifying and responding to students' needs and supporting help-seeking. It has also been argued that divergent patterns of group engagement with task content might reflect different perceptions of collaborative learning and that group work does not necessarily imply collaborative learning. Hence, divergent interactional practices may be adopted by different groups working on the same assignment, as students are generally not taught how to recognize, engage in, and utilize collaborative learning to enhance their learning (Summers \& Volet, 2010). Therefore, teachers play an important role, as teacher support influences student participation and achievement (Webb et al., 2019).

Interestingly, while teachers tend to focus on students' cognitive activities rather than their social activities, they are more likely to get involved with groups that exhibit higher student activity (Van Leeuwen et al., 2013). This implies that student groups that succeed in collaborating and engaging with a task often obtain more attention from their teacher. This is critical, as students with low subject self-efficacy need and benefit from teachers' emotional support, strengthening their emotional and social engagement (Martin \& Rimm-Kaufman, 2015). Moreover, when students lack deep domain knowledge and a repertoire of disciplinary practices, guidance may be particularly essential (Vauras et al., 2019). Balancing student needs and guidance in collaborative learning demands competences and practices that teachers may not have necessarily mastered or do not apply pervasively.

Well-designed CSCL environments for collaborative inquiry learning and problem-solving in science with supportive technological tools, such as simulations and virtual laboratories, can enhance learning when used in conjunction with teacher provided instructional support. In a recent meta-analysis, Chen et al. (2018) found that the use of CSCL was related to better knowledge gains, skill acquisition, positive perceptions of collaboration, group task performance, social interaction, and learning outcomes than individual CSL. They also found that computer use can generate an active learning approach, increase levels of interest, and develop high-level thinking. Situational and individual elements, such as motivation, opportunities for social interaction, experiences of flow, and the environment itself, influence students' responsiveness in CSCL. The ability to make active decisions and be in control positively affects learning outcomes, whereas insecurity, lack of confidence in knowledge and abilities, and a variety of options within the computer-supported environment may be detrimental (Ainley \& Armatas, 2006).

As the use of technology in learning does not automatically result in engagement in learning activities and better learning outcomes (Sinha et al., 2015), it is important to note that some students are not eager to learn from a technology-integrated constructivist approach (Tondeur et al., 2017). Further, students' interactions may not show evidence of collaboration, as the fostering of collaborative skills is not embedded in CSCL. A study by Kwon et al. (2014) on a CSCL group project in medicine found that most of the groups did not demonstrate ideal collaborative interaction patterns. This finding suggests a lack of collaborative skills among undergraduate students, and thus the importance of the teacher as an instructor and facilitator of both content learning and collaboration. 
Although technology-enhanced learning environments may have built-in scaffolding features, students may not be able to benefit from them as they are unfamiliar with the environment or lack needed supplementary information. Thus, a human coach plays a crucial role in both individual and collaborative learning activities (Dillenbourg, 2008; Greiffenhagen, 2012). In scientific inquiry, the scientists explain phenomena in the natural world based on their empirical findings, whereas inquiry learning refers to a learning process where students solve complex problems, engaging in reasoning and explaining their conceptualizations as the teacher is directing their learning. As team work is a crucial part of scientific inquiry, inquiry learning has adopted collaborative learning as part of the learning process. In doing so, the aim is also to enhance the learning through co-construction of knowledge and understanding, mutual help and support, with the goal of gaining better performance than would have been possible independently (see, Kirschner et al., 2006). Technological tools, such as virtual laboratories, have enabled implementation of scientific inquiry to the learning process, providing more authentic learning opportunities also in the classroom context. In such technology-enhanced, collaborative inquiry learning, the role of the teacher is to support and guide the collaboration process as a facilitator, deemphasizing the role of a knowledge expert (Hsieh \& Tsai, 2012). However, while studies on teacher intervention in students' collaborative learning activities have been rare in the early CSCL tradition (Greiffenhagen, 2012), more emphasis has recently been placed on the role of teacher support and guidance activities in technology-enhanced learning environments (e.g., Janssen et al., 2012; Vauras et al., 2019). Studies relating teacher guidance and support exhibit ample variation in content. The research findings emphasize, for example, classroom organization, instructional and emotional support (Hamre et al. 2013), management of the science ideas, instructional materials, tasks, students, and the overall social context during inquiry-based science instruction, all with the goal of supporting and sustaining learning (Harris \& Rooks, 2010). Supportive teacher practices build and maintain rapport while engendering understanding and classroom management (Anderman et al., 2011). It has been argued that learning related social support can be divided into instructional, emotional, appraisal, and instrumental support (Malecki \& Demaray, 2003; see also Tardy, 1985). In addition, a more content-focused approach to classroom practices, and to the collaborative learning in particular, asserts that during collaborative learning the teacher starts with a whole-class introduction, then walks around the classroom, monitoring and assessing group performance, maintaining order in the classroom and making whole-class announcements during the group work (Greiffenhagen, 2012). Yet, a more coherent understanding for teacher guidance and support is needed. Accordingly, there is a growing literature on the concept of orchestration, which involves the complex role of the teacher guiding multiple groups at the same time. The support provided by the teacher in order to manage the guidance and support required for a multifaceted classroom activity are viewed as orchestration tools, with or without technology (see e.g. Dillenbourg \& Jermann, 2010; Van Leeuwen \& Rummel, 2019). However, not all collaborative classroom activities where small groups use material tools or are engaged in laboratory activities, have orchestration tools for the teacher and thus, it is of interest to examine teachers' guidance in these circumstances.

\section{Teacher efficacy, beliefs and affect}

Teacher support and guidance is influenced by teachers' own efficacy beliefs and affect. Empirical evidence from classroom studies shows that high school teachers' self-efficacy 
has a positive impact on students' motivation and achievement (Mojavezi \& Tamiz, 2012). Similarly, with respect to teaching in technology-enhanced learning, Ertmer and Ottenbreit-Leftwich (2010) argue that effective use of technology in the classroom is deeply intertwined with not only teachers' knowledge and skills but also their self-efficacy and pedagogical beliefs. Further, teachers' self-efficacy to teach with technology is more important than their competency with technological tools. In their review, Tondeur et al. (2017) explain how continuous technology usage and school culture can transform teachers' more traditional pedagogical beliefs into more student-centered constructivist beliefs. At the same time, they highlight the variation across teachers, even within the same school. When teaching in technology-enhanced learning is combined with inquiry learning, a more comprehensive understanding is desirable. As teacher beliefs are reflected in teacher practices, teachers with an understanding of inquiry-based learning and technology use have a better understanding of instructional principles and thus produce principle-based practice patterns, and thus influence student outcomes (Song \& Looi, 2012).

While providing help, advice, instruction, and support for students in the classroom, teachers also project their own attitudes and feelings. There is a growing body of literature concerning how teacher affect influences instructional activity. For example, positive affect is associated with student-focused teaching approaches (Trigwell, 2012) and with cognitive and motivational stimulation and social support (Frenzel et al., 2009). Reciprocally, teachers' emotional processes impact student affect and thus impact student engagement (Mazer et al., 2014). Consequently, it is plausible that a positive emotional tone in the classroom creates better learning opportunities and experiences for both students and teachers (Hagenauer et al., 2015; Meyer, 2014). Similarly, just as teachers' affect influences their teaching approach, instructional behavior, and students' affect (Becker et al., 2014), so it also affects teacher perceptions of student performance, motivation, and discipline (Zembylas, 2002). In turn, student engagement and teacher-student relationship (Demetriou \& Wilson, 2009; Hagenauer et al., 2015) influences teacher affect. Accordingly, the interaction between the teacher and the students along with their affect have a reciprocal positive or negative impact on instructional behaviour and learning in the classroom. The aspect of congruence between students' perceptions and teachers' own perceptions of their affect and guidance has been a rather neglected area in studies of teacher affect (see, e.g., Hascher, 2010). Although the literature related both to students' and teachers' affect connected with inquiry learning is extensive, studies on teachers' and students' perceptions of affect have mainly combined students' perceptions of their own affect together with their perceptions of teacher affect (see, e.g., Becker et al., 2014; Jiang et al., 2016; Trigwell, 2012). Studies that combine both students' and teachers' perceptions of their own affect in collaborative inquiry learning in VLE are almost non-existent.

There is a continuous need to examine various discrete teacher emotions in the classroom (see, Frenzel, 2014). Accordingly, the present study adopted a discrete emotion approach in order to investigate the insights of certain affective states during teaching in the classroom. With the understanding that affect is not stable, but changing over time (see, Ahmed et al., 2010), utilizing multiple measurement points is valuable for displaying a more comprehensive perspective on affect in the classroom.

Furthermore, there is a paucity of literature on how affect is related to teacher activity and, reciprocally, to student feelings in novel, technology-enhanced collaborative learning environments (see, e.g. Slakmon \& Schwartz, 2019). Additionally, affect is seldom under scrutiny in CSCL research or in educational papers partly due to practices in cultural-historical activity theory that aim to gain objectivity and scientific generalization by eliminating subjectivity (Roth, 2007; see also Holzkamp, 1991), and 
the idea that affect interrupts the actual learning process (Schuman \& Scherer, 2014). This perception has lately morphed into an understanding that affect, cognition, and motivation are inseparable aspects of learning (Kim \& Pekrun, 2014). Nevertheless, since the theoretical (see Schuman \& Scherer, 2014) and conceptual groundings (see, e.g., Efklides, 2017) remain somewhat ambiguous, research on affect related learning especially in CSCL is scarce and thus of interest.

\section{Study aim and research questions}

The aim of the study is to extend our understanding of the teacher's role in collaborative, virtual, hands-on experimentation of ocean acidification, which combines biology and chemistry. Although teachers are considered important facilitators of technology-enhanced collaborative inquiry (Dillenbourg, 2008; Hsieh \& Tsai, 2012), few studies have looked at how they intervene in collaborative learning activities (Greiffenhagen, 2012), especially when orchestration tools are not available for the teacher in guiding the collaborating groups in the VLE. Ocean acidification as a learning and teaching phenomenon creates challenges especially with respect to virtual hands-on experiment due to the interdisciplinary nature and scarcity of proper VLE, along with the aim to provide student-active forms of learning and exploratory activities (see, Fauville et al., 2013). Some studies indicate that effective collaborative learning instructors can benefit from well-designed material and technological tools that allow them to guide student teams in disciplinary activities (e.g., Vauras et al., 2019). However, school expectations may interfere with a teacher's role as an effective instructor and therefore negatively influence the provision of engagement opportunities (see Lo \& Tierney, 2017). Consequently, the feelings and emotions of teachers that arise in these contexts deserve attention, as does student affect, which might also be viewed as a reflection of teachers' guidance and affect (see, Jiang et al., 2016).

The present study adopted a mixed-method approach, leveraging both video and questionnaire data to provide an in-depth understanding of the target phenomenon (see Turner $\&$ Meyer, 2000). The study explores the real-time division and focus of teacher guidance and support, which are associated with teachers' assessment of their own guidance and affect when working with collaborative groups. Teacher support is also explored as it relates to different attributive properties of student groups and group achievement.

In addition to a systematic analysis of the focus of teacher support, concepts from social network analysis (SNA), such as the centralization of interaction, were applied. This approach made visible the distribution of teacher support across distinct groups. Three research questions were formulated, as follows:

1) What is the nature and magnitude of teacher guidance and support that emerges across different classrooms?

2) How are teacher guidance and support distributed among the student groups? How is the distribution of teacher support related to groups' motivational features, prior science competence, and outcomes?

3) What is the nature of the relationship between teachers' perceptions of their own affect, guidance, and support and that of their students' self-reported affect? 


\section{Participants}

The participants of this study were four high school science teachers and the students they taught in each of their four classes $(\mathrm{N}=56)$. The students were 16- to 18 -year old senior high school students pursuing advanced biology or chemistry classes. Two of the science teachers had majored in biology (pseudonyms Paula and Henrik) and two in chemistry (pseudonyms Elisa and Leo). With respect to their expertise, particularly their disciplinerelated content knowledge, Paula and Leo were experienced biology and chemistry teachers, respectively, whereas Henrik and Elisa were at the beginning of their respective careers. Regardless of the level of their experience, all the teachers were novices at guiding students in VLEs. The composition of the VLE used in this study supported structured inquiry (see Windschitl, 2003).

The teachers sorted the participating students into 19 small groups of three, and two pairs. When forming groups, students' disciplinary knowledge and English language background were balanced to assure equal learning opportunities for the groups. As the study was an integral part of their course, the students received course credit for their participation.

Participation was voluntary for all participants. All teachers and students (or, if minors, their legal guardians) gave written consent, which included permission to videotape all work. Video material was processed privately by the authors only. All coded data were anonymized, and pseudonyms were used to identify teachers. All material was stored according to the regulations. Ethical principles were stringently followed in accordance with the university and national guidelines.

\section{Learning environment}

The Virtual Baltic Sea Explorer (ViBSE), a web-based learning environment, was used in this study. It was designed by professionals in education, biology, and chemistry to create a virtual expedition in a research vessel to study environmental changes in the Baltic Sea. The VLE provided a virtual laboratory for experiments, information, and material from an authentic research vessel, $\mathrm{R} / \mathrm{V}$ Aranda, including interviews and a library that integrated topics on biology and chemistry. Authentic data from marine biology studies (Bonaglia et al., 2013; Engeström-Öst et al., 2014) provided the basis for the VLE to guide experimentation and conclusions. The main aim of the VLE was to scaffold collaborative learning to provide students with a deeper understanding of specific science phenomena through shared problematizing and integration of knowledge from two science disciplines. One challenge was that the environment was operationalized in a dominant science language, that is, English, instead of the students' native language.

\section{Procedure}

All teacher and student classroom activities were videotaped and audio-recorded. Students worked in the VLE during their regular lessons as part of their course. Information and guidance on how to use the VLE, as well as on how to collaborate as a "researcher team" 
(student task) and scaffold the collaborating teams (teacher task), were provided before the working period began.

The working period included three sessions of 75 to $95 \mathrm{~min}$. Each session followed one of the phases of scientific research: 1) hypothesis and experiment planning, 2) experimentation and analyses, and 3) conclusions and a joint group presentation. Each small group worked autonomously at its own table with a shared laptop, and teachers provided guidance and support when necessary. At the end of each session, the teacher completed a paper-and-pencil questionnaire, documenting their perceptions of the collaboration of each small group as well as their own affect and guidance. The students completed a paper-andpencil questionnaire on their affect similarly.

\section{Measures and data}

Group outcome was measured by the groups' jointly constructed PowerPoint presentations at the end of the working period, which reflected their learning and achievement. Two qualified science professionals in biology and chemistry evaluated the presentations on a 6-point Likert scale. Evaluation criteria included the structure of the presentation, understanding of the task, hypotheses, research plan, conclusions, and the contextual appropriateness of scientific language. The outcome levels comprised six levels ( $1=$ low-, $2=$ low,$+ 3=$ average-, $4=$ average,$+ 5=$ high-, $6=$ high + ). All groups were labeled based on their outcome level. The quantitative outcome measure (1-6) was used to separate the groups (e.g., High $_{6}=$ high outcome, highest outcome level).

Students' prior science competence was determined by their previous individual grades in biology and chemistry courses. The number of courses varied from two to five per student; hence, an aggregated mean grade was computed to indicate the group's prior science competence.

Students' affect was assessed using a systematic paper-and-pencil questionnaire that students completed independently after each working session. The affect scale was based on the valence of positive and negative affect, using a 10-point bipolar Likert scale, evaluating 12 items from the orthogonal positive and negative affective states, representing 24 affective states, e.g., enthusiastic-bored, excited-tired, satisfied-frustrated (see Pietarinen et al., 2019). For frequency analyses, values ranging from 1 to 4 were classified as negative, 5 to 6 as neutral, and 7 to 10 as positive. The affect scale measured valence (orthogonal positive and negative affective states) and arousal (activating and deactivating affective states) based on the circumplex model of affect (Feldman Barrett \& Russell, 1998; LinnenbrinkGarcia et al., 2011; Scherer, 2005). The measure of the collective affect of a student group was an average of the members' values. The teacher's evaluation form was a three-part questionnaire used at the end of each working session. First, the teachers assessed their impressions of how each of the groups performed. The questions comprised a 10-point bipolar Likert scale (four items) assessing collaboration: Easily grasped demanding challenges/Avoided challenges and Favored working alone/Favored collaboration; the valence of collaboration: Worked negatively and non-enthusiastically/Worked positively and enthusiastically and Unmotivated and off-task/Strongly motivated and on-task. These four items were divided into two components: collaboration and motivation and emotional valence. Second, the teachers assessed their own guidance and support of the student groups on a 10-point Likert scale (six items); for example, I found it easy to observe separate groups/I found it difficult to observe separate groups. For the frequency and SNA, values ranging 
from 1 to 6 were classified as low, 7 to 8 as average, and 9 to 10 as high. Third, teachers were asked to assess their own affect while working with the groups using a systematic affect scale based on the valence of positive and negative affect of a 10-point bipolar Likert scale in the same manner than students' assessment (six items); calm-tense, glad-irritated, enthusiastic-unenthusiastic, satisfied-unsatisfied, energetic-tired, confident-insecure. For the frequency and SNA, values ranging from 1 to 4 were classified as negative, 5 to 6 as neutral, and 7 to 10 as positive. The teachers' evaluation form on affect and guidance was constructed identically with students' evaluation form, which has been validated with SEM analyses and strengthened with video observations (see, Pietarinen et al., 2019, 2020).

Video observations on the distribution of teacher guidance and support of the groups were executed by calculating systematically the number of times a teacher visited each group and the number of times a teacher visited a group that requested the teacher's attendance in their group conversation to provide guidance and help. The applicable video data for each teacher, including guidance given to the whole class and the individual groups and observance of group progress, were as follows: Paula $2 \mathrm{~h} 14$ min $23 \mathrm{~s}(60 \%$ of total $3 \mathrm{~h}$, $42 \mathrm{~min}, 26 \mathrm{~s}$; total time = all activity in the classroom, including time spent answering the questionnaires); Henrik 2 h 16 min 26 s (58\% of total 3 h, 55 min, 31 s); Elisa 1 h 23 min $30 \mathrm{~s}(46 \%$ of total $2 \mathrm{~h}, 59 \mathrm{~min}, 47 \mathrm{~s}$ ); and Leo $1 \mathrm{~h} 15 \mathrm{~min} 53 \mathrm{~s}(38 \%$ of total $3 \mathrm{~h}, 18 \mathrm{~min}$, $24 \mathrm{~s})$.

Coding for the focus of teacher guidance and support was based on previous findings in the literature, highlighting socio-emotional, instructional, cognitive (the task), and classroom management (e.g., Anderman et al., 2011; Malecki \& Demaray, 2003), and supplemented with technical guidance as an essential dimension in CSL. The focus of teacher attention was coded based on verbal interactions between teachers and groups, illustrating the nature of guidance and support. Teachers' real-time activity and the focus of teacher attention was documented systematically from the videos, using mostly videotapes capturing the whole classroom activity. The coding was challenging, thus requiring repetition and in unclear cases, videotapes from a specific group were used to clarify the reason for a teacher's visit. A moment-to-moment activity coding aggregated a total of 913 activity sequences. An extract from the detailed coding form is presented in the Appendix Table 3. The coding for focus of teacher verbal guidance and support during the specific virtual inquiry learning in all four cases was defined as a choice between technical, content knowledge, task management, socioemotional support, off-task discussions, and general guidance for the whole class (see Table 1). Verbal guidance and support were supplemented with observing, designated as when a teacher paid silent attention to a particular group. In-depth elaboration on student activity in the groups as well as insights into students' affect and collaboration can be found from Pietarinen et al., 2020.

\section{Analyses}

The data for the SNA was collected by the video observations, see Table 1, regarding the four science classrooms. The data was coded as square matrices, one for each class, so that the teacher and the groups were placed both on the rows and columns, and the cells of the table indicated frequency of interaction. A standard network analysis software, UCINET (Borgatti et al., 2002), was used to model network topography for each teacher's connections to the student groups in their classroom. In this study, the focus was on the number of connections made between teachers and the student groups in their classroom (i.e., not between the student groups) and how they were distributed in terms of centralization of interaction. 


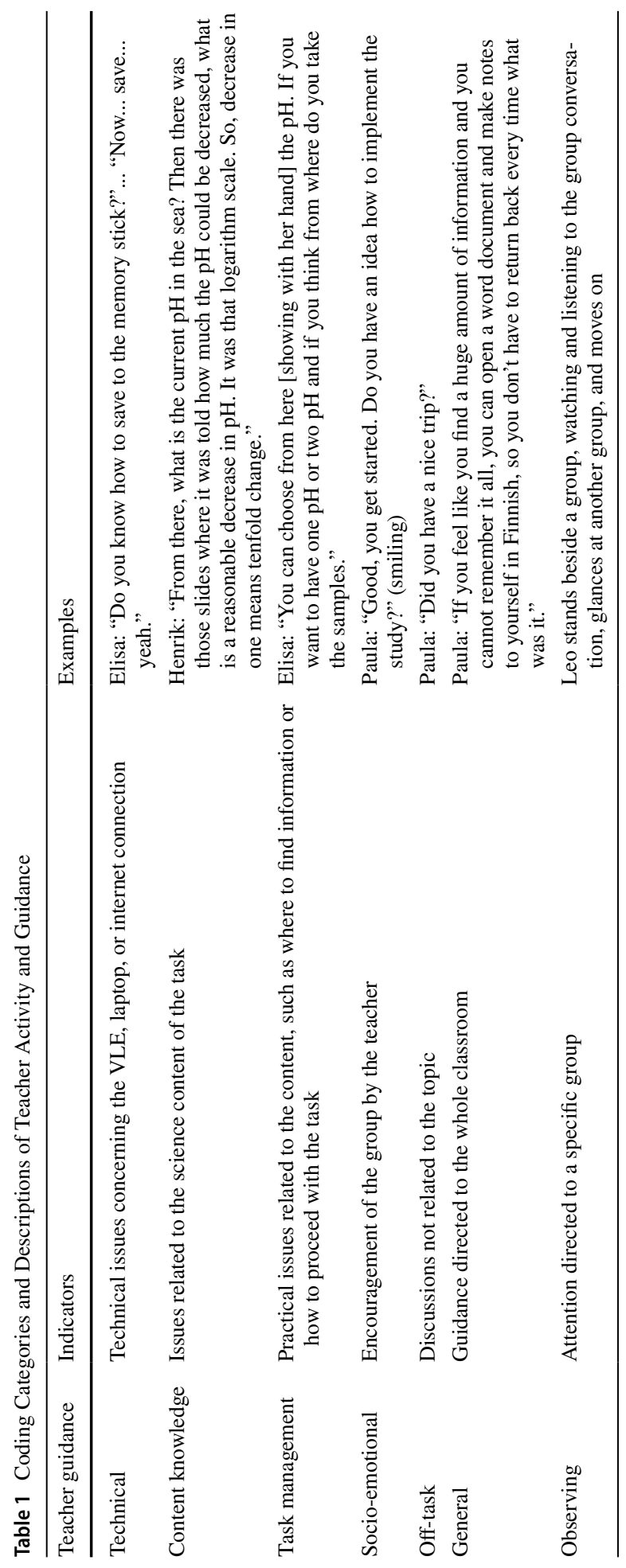


The SNA was executed using the square matrices and including the following categorical variables: i) student groups' prior science competence (aggregated grade means reported by the students themselves, high/average/low); ii) teachers' perceptions of each group (questionnaire data high/average/low, including collaboration and socioemotional evaluation); and iii) group outcome (evaluated by the experts, high/average/low). The distribution of teachers' communication with the student groups in their classrooms (SNA data) was tested by Blau's heterogeneity measure to see which factors (categorical variables), if any, influenced the centralization of interaction.

\section{Results}

\section{The focus of teacher guidance and support in different classrooms}

Taken together, almost half of the working period (48\%) was spent providing support in task management (20\%), content knowledge (13\%), and technical guidance (15\%). However, the teachers observed the groups rather intensively (40\%), as can be seen in Fig. 1. Off-task discussions (4\%) and general guidance (4\%) for the classroom (typically occurring at the beginning and end of the working period) were rare. Somewhat surprisingly, teachers' socio-emotional support was minimal (4\%) despite the fact that the students were working in a new and challenging learning environment. The duration of teacher guidance and support activity sequences varied between $1 \mathrm{~s}$ to $5 \mathrm{~min}$, general guidance excluded. The longest sequences were in content knowledge, task management and technical guidance, respectively.

Visible variance was observed between the teachers regarding their guidance and support (Fig. 2). With respect to content-related guidance, Paula and Henrik spent most of their time supporting content knowledge construction. Paula visited her groups often but

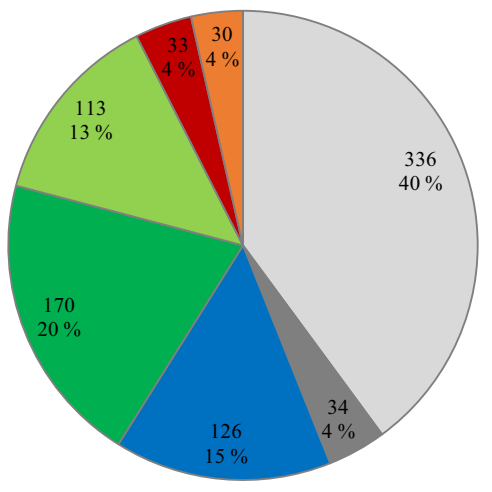

$\square$ Observing $\square$ General $₫$ Technical $\square$ Task management $\square$ Content knowledge $\square$ Socio-emotional $\square$ Off-task

Fig. 1 Total amount of teacher guidance and support in all four classrooms in frequencies $(f)$ and percentages $(\%)$ 

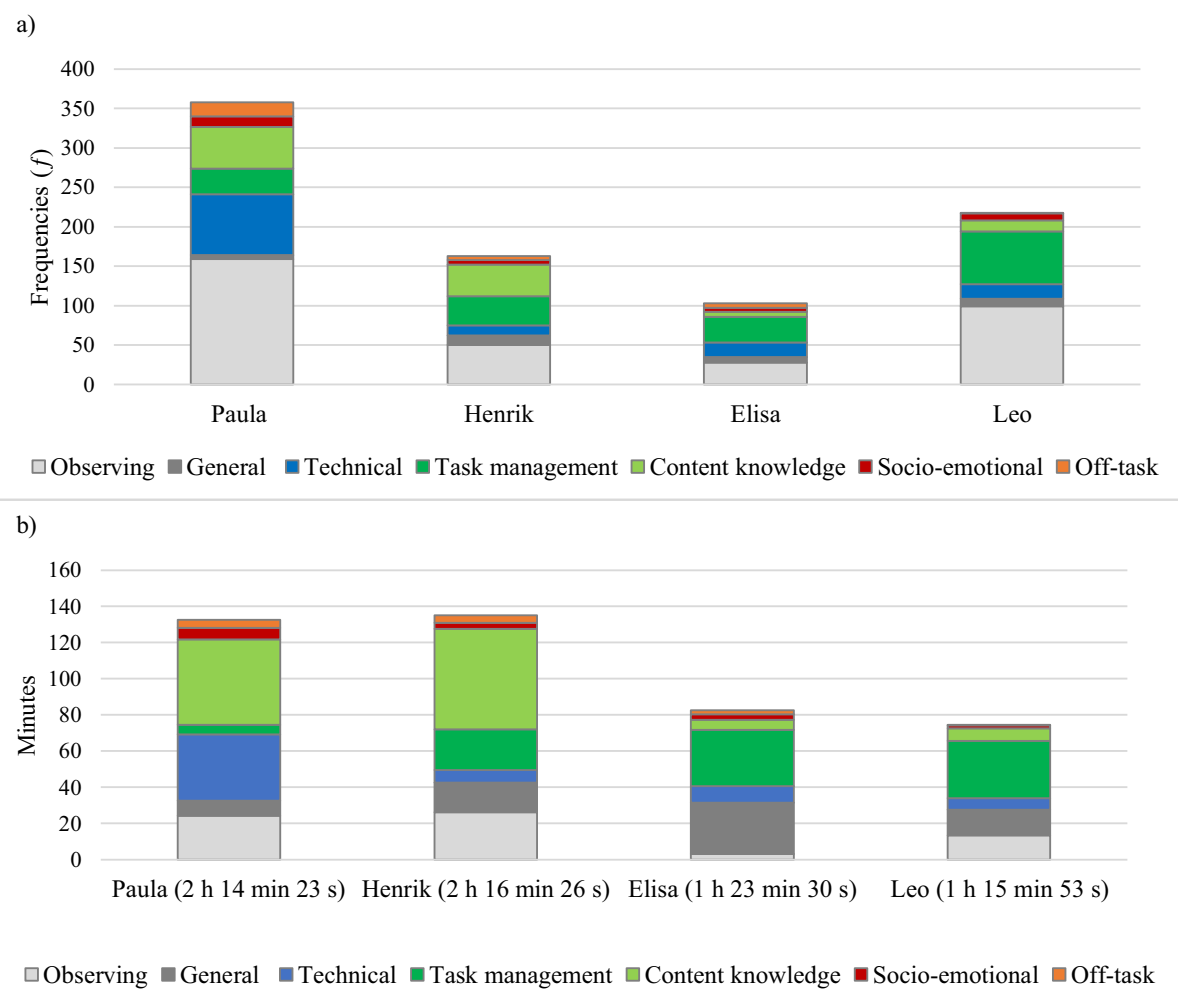

Fig. 2 Teachers' guidance and support in four classes $(f)$ and the duration of attention in minutes

briefly, whereas Henrik's visits were rare but more sustained. In comparison, Elisa and Leo provided little guidance related to content knowledge. Instead, they spent most of their time guiding task management. Henrik and Paula guided their groups in task management issues as often as Elisa did, but their visits were much shorter.

With respect to technical guidance, Paula spent the most time and visited her groups often to provide technical assistance. For the other teachers, technical guidance was a minor issue. The teachers seldom provided general guidance. However, Elisa spent $34 \%$ of her guidance time explaining general issues to the entire class but observed her groups remarkably rarely. The other three teachers observed their groups for about the same amount of time. Overall, Paula visited her groups most often, and her guidance and support were fairly equally distributed between content and technical issues, whereas the other teachers visited their groups less frequently and focused mainly on content or task-related issues.

\section{The distribution of teacher guidance and support for the distinct outcome groups}

There were differences between the classrooms regarding group outcomes, irrespective of the teachers' core discipline (biology or chemistry) (Fig. 3). All three outcome levels (high, average, and low) were present in Paula's and Elisa's classes, but only average and low outcomes were present in Henrik's and Leo's classes. Considering content knowledge, which 


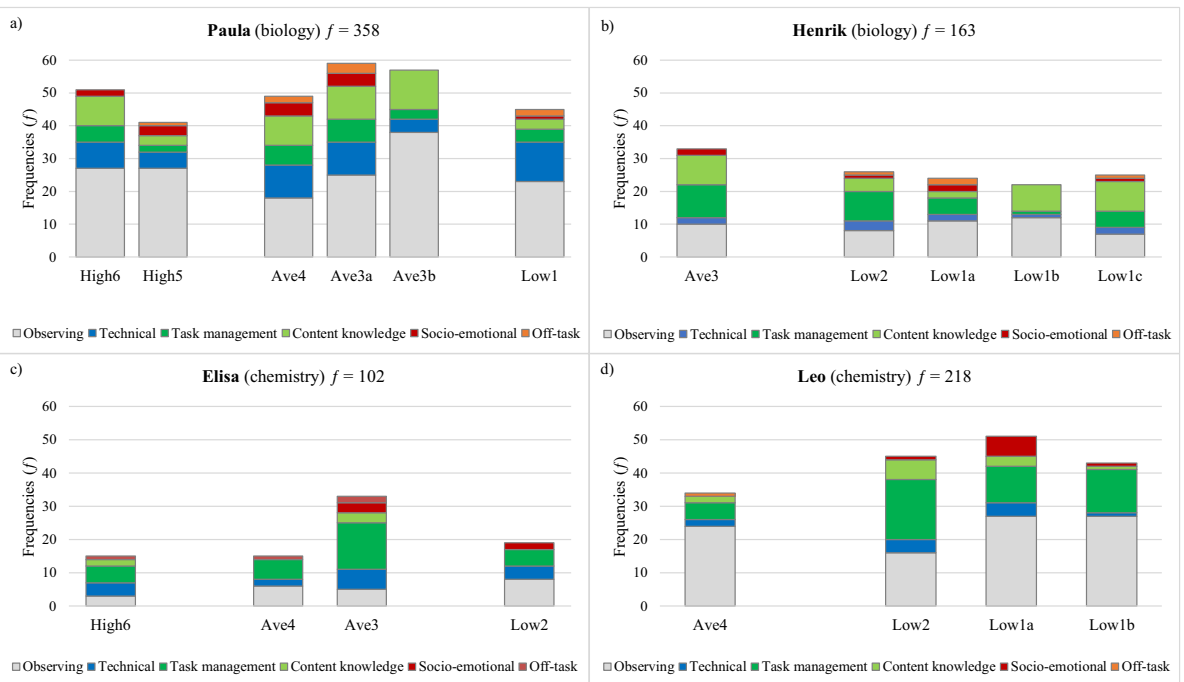

Fig. 3 Teachers' support for the small groups $(f)$ in four classrooms. Group codes designate group outcome level (high 6-5/average 4-3/low 2-1)

Paula and Henrik spent more time on than the others, the different outcome groups all received support but with varying numbers of visits. Leo provided content knowledge support to all groups, whereas Elisa only did so for two groups, leaving one average group as well as the only low outcome group without support.

Further, all 19 groups received technical guidance, and their progress was observed within varying periods. Notably, one group in each of three classrooms did not receive any socio-emotional support. In Elisa's classroom, the two best outcome groups were left without any socio-emotional support. Regarding off-task discussions, Leo talked only with the best outcome group in his classroom. Elisa did not have off-task discussions with the weakest group. In sum, all teachers observed their groups and provided guidance and support for task- and technical-related issues, but socio-emotional support and off-topic discussions were only realized with some groups. Notably, the best performing groups did not receive more guidance and support than the other groups when comparing the number of visits per group, except in one case in which Henrik guided the best performing group the most.

We also looked at whether the teachers shared their guidance and support in an equitable way driven primarily by varying group attributes (see Table 2 for categories). Teacher guidance was quantified based on frequency of interaction, that is, how many times the teacher was in contact with a group, rather than on the amount of time spent with the group. Blau's heterogeneity measure applied across teachers revealed that they differed in terms of how equitably they visited the groups (see Table 2). For results related to the group outcome (high/average/low), Paula and Elisa guided their small groups rather equally. For Henrik and Leo, interpreting the results is difficult due to small group outcome variance. A low support and guidance level seemed to be associated with homogeneity and low group outcomes (i.e., unequal distribution in interaction appeared biased toward low achievers, but the causal explanation for this is unclear). Furthermore, the most notable differences in teacher guidance and support in the classroom related to teacher perceptions of group collaboration, as teachers frequently guided the groups that they perceived as most willing 


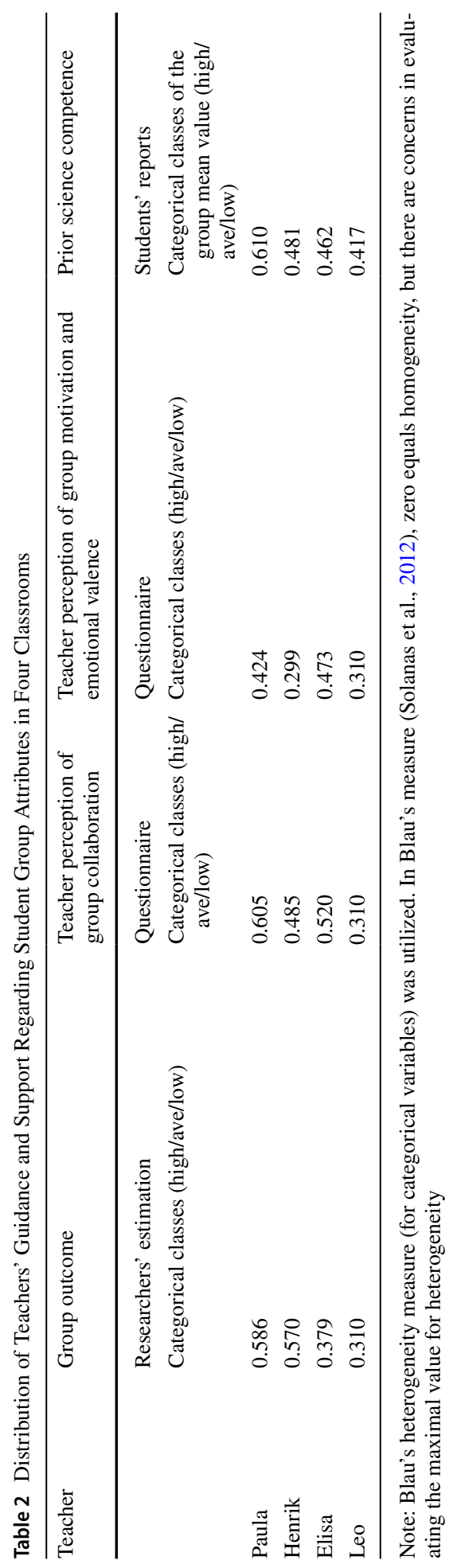


to collaborate. Only one teacher, Elisa, exhibited variation in her guidance and support for small groups with respect to her perceptions of motivation and socio-emotional valence in the groups. Regarding the groups' prior science competence, Paula's guidance and support strategy differed from other teachers, as her groups were the most equally distributed in terms of level of prior science knowledge.

\section{Teachers' perception of their own affect and their guidance in relation to their students' self-reported affect}

To understand the guidance and support provided by the four teachers, teachers' perceptions of their own affect and guidance were examined using the questionnaire data from three measurement points (taken at the end of the planning, experimentation, and conclusion phases). Paula reported a positive initial phase for her guidance, but more challenges arose during the experimentation phase. She confronted challenges in providing guidance and support, such as difficulty integrating biology and chemistry, providing good hints for the groups, and intervening in group collaboration. Eventually, during the conclusions phase, her perception again became more positive. Paula showed only a positive selfreported affect (activated-deactivated-combined).

In comparison, Henrik reported equally positive and negative perceptions with respect to his guidance, indicating challenges in noticing when his guidance was needed, following the groups' progress, and guiding the groups. He also experienced challenges in integrating biology and chemistry throughout the guiding process. Henrik's perception of his own guidance collapsed toward the end, as he reported dominantly negative perceptions of his own guidance, indicating difficulties in determining when and how to guide the groups. His self-reported affect showed a notably high proportion of negative affect (nearly half), compared to the other teachers, and most of the affect he reported was deactivating in nature (positive-negative-combined). He repeatedly reported being unenthusiastic and tired. He also expressed some insecurity and irritation, as well as some excitement at the end.

Elisa perceived her guidance as mainly positive at the start but more negative later on. She experienced some minor challenges in giving hints, knowing when to avoid intervening in groups' collaboration, and identifying when her guidance was needed. Like Paula and Henrik, she experienced some difficulty integrating biology and chemistry. Regarding affect, Elisa reported some negative activating affect at the beginning of the working period, indicating discontent, but her affect became more positive during the last two phases.

In contrast, Leo showed only a positive affect and a strikingly positive perception of his guidance. He experienced only minor difficulty in knowing when to avoid intervening in the groups' performance. Self-reports of teacher guidance and affect are presented in Fig. 4.

Finally, the affect of all students in the four classrooms was analyzed, demonstrating a relationship between teacher and student affect (Fig. 5). Students reported similar affect during the planning phase; differences emerged during the experimentation and conclusion phases. Although Paula reported having a very positive affect throughout the working period, her students' affect corresponded more closely with Paula's perceptions of her 

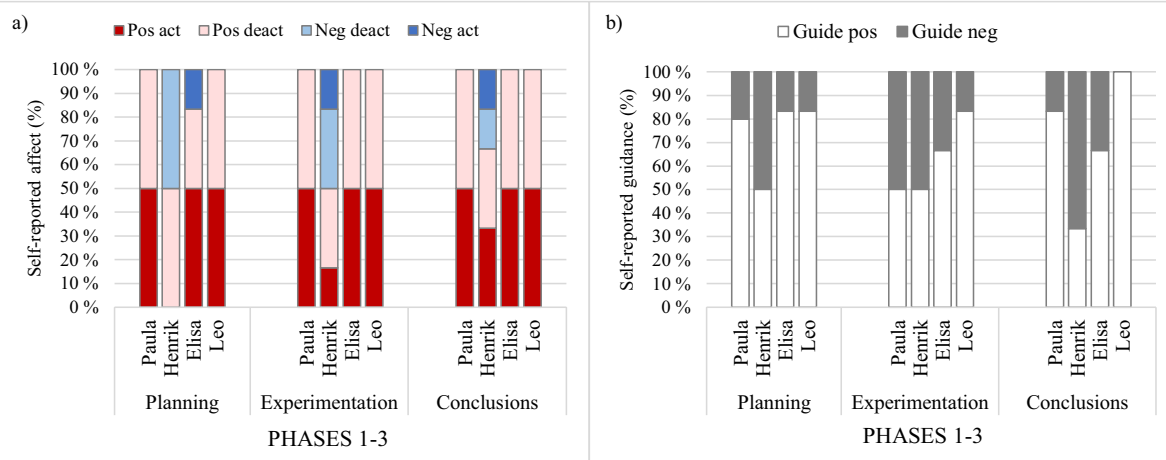

Fig. 4 Teachers' self-evaluated affect and guidance (\%) during the three working phases

guidance. The students' affect was slightly negative during the planning and experimentation phases but more positive during the conclusions phase.

Henrik had a negative perception of his affect and guidance. His students' perceptions were in line with his, though not as intense. Elisa's students reported rather stable affect throughout the working period, remaining mostly positive and only occasionally negative. There was more variation in Elisa's perception of her affect and guidance: she reported some negative affect during the planning phase, and her perception of her own guidance became more negative during the experimentation and conclusions phases. In contrast, Leo reported a very positive affect and perception of his own guidance. However, Leo's students reported some negative affect during the planning and conclusion phases, despite Leo's perception that his guidance was nearly perfect during this time.
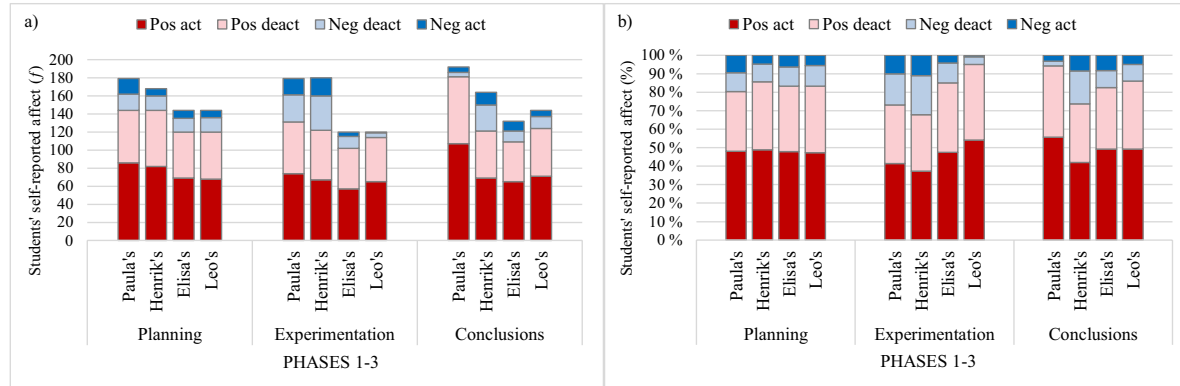

Fig. 5 Students' self-evaluated affect in four classrooms in frequencies $(f)$ and percentages $(\%)$ in three working phases $(\mathrm{N}=56)$ 


\section{Discussion}

This study focused on the real-time guidance and support provided by science teachers during in-classroom small group CSCL. A multimethod analysis demonstrated the realtime focus and distribution of teachers' guidance and support between different small groups in their classrooms, and the reciprocal relationship between teacher and student affect. Our findings contribute to our currently limited understanding of teachers' role in facilitating CSCL in science and the multifaceted and complex nature of classroom activities and instruction.

\section{Real-time emergence of guidance and support in the classrooms}

Teachers were highly instruction oriented, as evidenced by rare off-task discussions with the students. As expected, whole class general guidance was subordinate to guidance for individual groups. However, when paying attention to groups, teachers spent more than a third of the time observing group performance. This may partly reflect teachers' understanding of the guidelines' suggestion not to control but rather to guide and support as needed; however, the act of guiding students in collaborative inquiry learning in a VLE they were unaccustomed to likely also influenced teachers' activity. Also the rather demanding topic of ocean acidification that combines two science disciplines, biology and chemistry, might have influenced teachers' guidance and support, as they had majored only in one discipline. The findings from teachers' self-evaluation support this assumption. However, all four teachers did have the same strategy during the lessons, as they started with a joint introduction, then walked around the classroom, observing and assessing group performance and occasionally making whole-class announcements, which is in line with the empirical findings of Greiffenhagen (2012). When teachers were walking around the classroom and observing the groups, they regularly stopped by a group, provided help if needed, and then followed the group activity for a while assuring that the group could proceed without further problems. Typically the teacher left the group only when the target problem was solved and the group was ready to continue their collaboration. Thus, the groups were not left prematurely without guidance because of a need arising within another group.

When providing support, the teachers spent only a third of their time on the actual science tasks, that is, supporting either task management or content knowledge. To some extent, support related to the actual task content was likely hindered by technical issues, which demanded a fair amount of teacher assistance. The teachers' own perceptions of their guidance support these assumptions.

Furthermore, the teachers only occasionally provided socioemotional support to the groups. This observation might be of concern and important to explicitly study in the future, as high-level emotional support from a teacher can enhance emotional and social engagement and compensate for students' feelings of low self-efficacy (Klem \& Connell, 2004; Martin \& Rimm-Kaufman, 2015). Stronger socio-emotional support would enhance student engagement and self-efficacy, and consequently, the collective outcome of the less successful groups. Relationally small amount of support for student groups may have 
been due to teachers misinterpreting group behavior or progress (e.g., a group may have appeared to be on-task and may not have asked for guidance directly) or being inattentive in observing a particular group's activities.

The guidance and support of the teachers' was not connected to the group outcome level. Interestingly, both video analyses and SNA revealed that teachers eagerly guided groups that they perceived as active and more willing to collaborate, although this effect was not systematically found for all teachers. This finding is consistent with earlier research suggesting that teachers get more involved with high-activity groups (Van Leeuwen et al., 2013). Selective attention, directed mainly at small groups already successfully engaged in the task, can be detrimental if the group lacks competence regarding the topic or has low self-esteem (Martin \& Rimm-Kaufman, 2015). This highlights the importance of paying attention and providing support, both content and socio-emotional, to groups with low task-related self-confidence (see Pietarinen et al., 2020).

Some notable differences among teachers did occur. First, the time and distribution of teacher guidance for groups ranged from full-time attention to only half-time engagement. This finding is consistent with that of Osborne et al. (2013), who found that teachers differed with respect to their innovative pedagogical practices. In the case of the present study, the teachers had to adopt new pedagogical practices in what was for them a novel learning environment. Further, Osborne et al. (2013) found that these differences were compounded by school policy, departmental culture, and leadership style as well as by differences in teachers' expertise, beliefs, priorities, and teaching goals. Similar findings with respect to differences in teachers' scaffolding practices and affect related to chemistry and physics learning in the classroom have been found by Maria et al. (2003) and Ritchie et al. (2013).

In the present study, one of the teachers represented an almost ideal image of a guiding teacher with respect to the distribution and focus of guidance, resulting in rather satisfactory group outcomes. This pattern is in line with findings suggesting that the attention and time provided by the teacher are connected to higher academic achievement (see, Tennant et al., 2014) and students' motivation to engage in education (Zhang et al., 2012). Despite experiencing challenges and having the highest number of small groups, this teacher was able to successfully guide the groups toward their common goal. This is consistent with the findings of Song and Looi (2012) suggesting that teachers with an understanding of inquiry-based learning and technology use have a better understanding of instructional principles and are therefore able to adapt principle-based practice patterns, which in turn impact student outcomes. Evidently, in addition to distribution, the foci of guidance and support need to be considered in order to understand the impact of teacher support on academic achievement. Teachers' own perceptions of their guidance and support, along with self-reported teacher and student affect, shed further light on the complex relationship between guidance and learning outcomes. More successful teachers seemed to be reflective and questioned their current competences as instructors in a new educational environment. However, teachers' activities revealed a distinct portrait. For instance, high criticality in guidance and support together with a highly negative affect was associated with students' negative affect and the weak outcomes of the small groups in this study. This is in line with findings emphasizing how teachers' emotions and instructional behavior are related to students' emotions and thus academic performance (Becker et al., 2014) and how the emotional tone in a classroom impacts both the teacher's and students' experiences and 
learning (Meyer, 2014). It is also plausible that the groups with poor performance lacked confidence (see Pietarinen et al., 2019), possibly evoked by the teacher's hesitant behavior and moments of insecurity. In contrast, guidance and support perceived as extremely positive together with a purely positive affect was associated with students' reported negative affect. These findings are unexpected in light of collaborating groups' weak learning outcomes. One possible explanation stems from evidence suggesting that teachers' selfefficacy beliefs may be more important than their actual skills and knowledge when implementing technology in the classrooms (Ertmer \& Ottenbreit-Leftwich, 2010). Interestingly, highly positive self-reflections, likely reflecting high self-efficacy beliefs, and simultaneous "instructional loafing", were related to low distribution of guidance and support across groups and relatively low learning outcomes as a result. This finding might highlight teachers' limited view of inquiry-based instruction, lack in knowledge and strategies in implementation, even though they understand the importance of inquiry (Capps \& Crawford, 2013; DiBiase \& McDonald, 2015; Tseng et al., 2013). Further, if students are left without guidance and support during inquiry lessons, that can interfere with their learning (Furtak et al., 2012).

\section{Limitations and future directions}

The study provided insight into the real-time focus and distribution of science teachers' guidance and support during collaborative virtual inquiry learning in interdisciplinary VLE. However, methodological considerations place limitations on the conclusions that can be drawn from this study. As the purpose of the study was to capture all activity that occurred in distinct classrooms during the entire teaching and learning period, a qualitative content analysis of discussions between teachers and groups was not feasible. However, as teachers appeared to direct their guidance and support toward active and cooperative groups, future research should investigate the teacher guidance and support provided to less active groups (see Van Leeuwen et al., 2013).

Another limitation of this study was the small sample size. A larger sample of teachers and small groups could have revealed clearer patterns in teacher guidance and support and thus provided more generalizable results on teacher activity in the classroom. Despite this, this study offers insights into science teachers' real-time guidance and support in four distinct classrooms, combined with distinct outcome groups, and thus goes deeper than general conclusions would have. Moment-to-moment systematic analysis was executed at a detailed level of coding for every second of the videos. This level of detail and comprehensiveness lends a transparency to the data analysis, resulting in a form of reliability and validity in place of what might arise through triangulation in a more quantitative largescale analysis. Accordingly, this comprehensive approach was selected in order to enable replication of the study in the future.

SNA was implemented to extend our understanding of teacher guidance and support by capturing the real-time division and focus of teachers' guidance and support in this CSCL setting. Diversity and heterogeneity in teacher guidance were emphasized over homogeneity and biased guidance practices based on the analysis, and SNA was therefore demonstrated as an apt tool for this research. The idea of direction, which is central in SNA, was 
first introduced in early social support research (see Tardy, 1985) and is thus applicable for further investigation with respect to social interaction within the classroom.

Future studies should aim to gather more in-depth, multimethod evidence of the realtime division and focus of teachers' guidance and support in different CSCL contexts to enhance awareness of instructional patterns in CSCL and challenges in the implementation of unbiased practices. Further, the adaptability of teacher guidance and support was beyond this study. Teacher's intentions and thoughts are challenging to detect and therefore specific research methods such as eye tracking or think-aloud might help in the future in making the cognitive actions visible (see, van Leeuwen \& Rummel, 2019).

Moreover, teacher's and students' affect were measured in very general terms and were not related to the adaptability of the guidance. Hence, research that takes into account the reciprocal perceptions would deepen the understanding of the teachers' role in collaborative learning. However, the measures were proved valid in light of the literature when emphasizing the interconnection between teachers' affect, instructional behavior and student affect. Therefore it would be essential to further examine teacher and student affect in CSCL to deepen the understanding of the influence of teacher-student relationships, affect and instructional behavior in the classroom.

\section{Concluding remarks}

This study used a systematic approach to examine and characterize the real-time guidance and support that teachers provide to small groups during collaborative inquiry learning in interdisciplinary VLE along with teacher and student affect. Although teacher activity in the classroom always reflects teachers' individual perceptions and practices, this study provides evidence of similarities in teacher activity that occur in distinct classrooms and thus influence students and student learning.

Notably, despite challenging tasks and environments, socio-emotional support was found only occasionally in the classrooms and not distributed equally to all peer groups. This seems to imply that the teachers may not have been adept at encouraging and supporting group collaboration and engagement in modern learning environments. Similarly, and surprisingly, it was found that teachers were less inclined to guide groups experiencing more challenges and more eager to guide those they perceived as motivated and willing to collaborate. Such bias suggests that teacher guidance and support can deepen the differences between the groups and their activities instead of reducing obstacles to learning for those most in need. The mechanisms underlying this finding open new directions for future exploration of teacher support.

This study investigated both student and teacher affect as an important aspect of classroom climate that influences teaching and learning, addressing the reciprocal relationship between affect, guidance, and support. It was shown that the classroom is an emotional place where teaching and learning are intertwined, and both teacher affect and activity and student affect and activity interact, influencing learning performance and outcomes. Although the role of a teacher in CSCL has been emphasized in the literature, more empirical studies focusing on teacher guidance and support and reciprocal interaction within student groups in CSCL contexts are needed to understand the complex prerequisites for productive engagement and learning. 


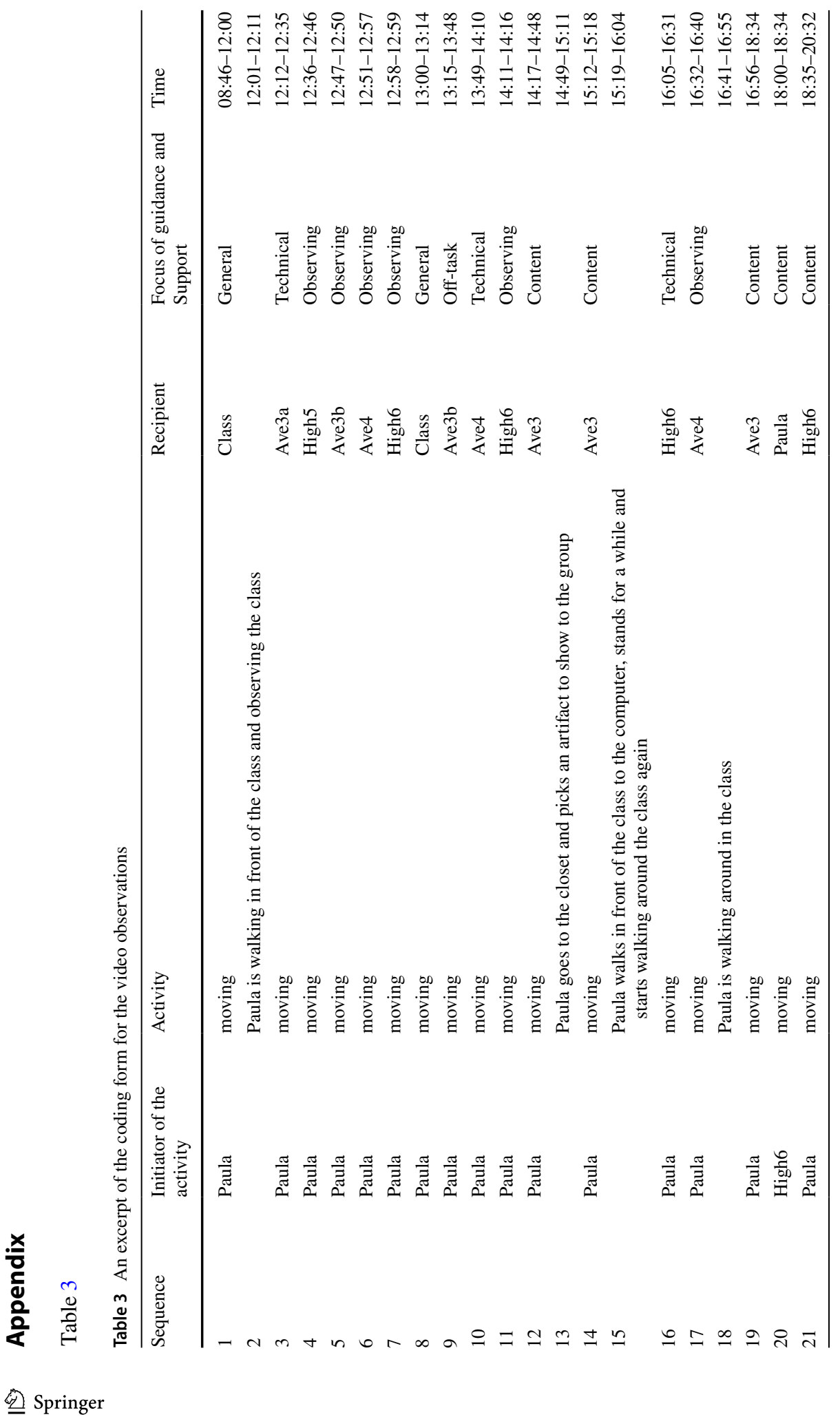


Acknowledgements The authors thank the teachers and students participating in this study, even if they remain anonymous.

Author contributions Tarja Pietarinen: Conceptualization, Investigation, Formal analysis, Writing-Original Draft, review, editing. Tuire Palonen: Conceptualization, Investigation, Formal analysis, WritingReview \& Editing. Marja Vauras: Conceptualization, Writing- review \& editing.

Funding Open access funding provided by University of Turku (UTU) including Turku University Central Hospital. This research was supported by grant No. 274117 from the Academy of Finland, awarded to the third author; and by grant from Jenny and Antti Wihuri Foundation, awarded to the first author.

\section{Declarations}

Competing interest The named authors have no competing interests to declare.

Open Access This article is licensed under a Creative Commons Attribution 4.0 International License, which permits use, sharing, adaptation, distribution and reproduction in any medium or format, as long as you give appropriate credit to the original author(s) and the source, provide a link to the Creative Commons licence, and indicate if changes were made. The images or other third party material in this article are included in the article's Creative Commons licence, unless indicated otherwise in a credit line to the material. If material is not included in the article's Creative Commons licence and your intended use is not permitted by statutory regulation or exceeds the permitted use, you will need to obtain permission directly from the copyright holder. To view a copy of this licence, visit http://creativecommons.org/licenses/by/4.0/.

\section{References}

Ahmed, W., van der Werf, G., \& Minnaert, A. (2010). Emotional experiences of students in the classroom. A multimethod qualitative study. European Psychologist, 15, 142-151. https://doi.org/10.1027/1016-9040/a000014

Ainley, M., \& Armatas, C. (2006). Motivational perspectives on students' responses to learning in virtual learning environments. In: J. Weiss, J. Nolan, J. Hunsinger, \& P. Trifonas (Eds.), The international handbook of virtual learning environments (pp. 365-394). Springer. https://doi.org/10.1007/ 978-1-4020-3803-7_15

Ananiadou, K., \& Claro, M. (2009). 21st century skills and competences for new millennium learners in OECD countries (OECD Education Working Papers No. 41). OECD Publishing. https://doi.org/10. $1787 / 218525261154$

Anderman, L. H., Andrzejewski, C. E., \& Allen, J. (2011). How do teachers support students' motivation and learning in their classrooms? Teachers College Record, 113, 969-1003.

Anderson, R. D. (2002). Reforming science teaching: What research says about inquiry. Journal of Science Teacher Education, 13(1), 1-12. https://doi.org/10.1023/A:1015171124982

Becker, E. S., Goetz, T., Morger, V., \& Ranellucci, J. (2014). The importance of teachers' emotions and instructional behavior for their students' emotions - An experience sampling analysis. Teaching and Teacher Education, 43, 15-26. https://doi.org/10.1016/j.tate.2014.05.002

Bonaglia, S., Bartoli, M., Gunnarsson, J. S., Rahm, L., Raymond, C., Svensson, O., Shakeri Yekta, S., \& Brüchert, V. (2013). Effect of reoxygenation and Marenzelleria spp. bioturbation on Baltic Sea sediment metabolism. Marine Ecology Progress Series, 482, 43-55. https://doi.org/10.3354/meps 10232

Borgatti, S. P., Everett, M. G., \& Freeman, L. C. (2002). Ucinet 6 for windows: Software for social network analysis. Harvard: Analytic Technologies.

Darling-Hammond, L. \& Bransford, J. D. (2006). Preparing teachers for a changing world: What teachers should learn and be able to do. Jossey-Bass.

Capps, D. K., \& Crawford, B. A. (2013). Inquiry-based instruction and teaching about nature of science: Are they happening? Journal of Science Teacher Education, 24(3), 497-526. https://doi.org/10.1007/ s10972-012-9314-Z

Care, E., Griffin, P., \& Wilson, M. (2018). Assessment and teaching of 21st century skills: Research and applications. Springer.

Chang, C.-J., Chang, M.-H., Chiu, B.-C., Liu, C.-C., Chiang, S.-H.F., Wen, C.-T., Hwang, F.-K., Wu, Y.-T., Chao, P.-Y., Lai, C.-H., Wu, S.-W., Chang, C.-K., \& Chen, W. (2017). An analysis of student 
collaborative problem solving activities mediated by collaborative simulations. Computers \& Education, 114, 222-235. https://doi.org/10.1016/j.compedu.2017.07.008

Chen, J., Wang, M., Kirschner, P. A., \& Tsai, C.-C. (2018). The role of collaboration, computer use, learning environments, and supporting strategies in CSCL: A meta-analysis. Review of Educational Research, 88(6), 799-843. https://doi.org/10.3102/0034654318791584

Chiu, M. M. (2004). Adapting teacher interventions to student needs during cooperative learning: How to improve student problem solving and time on-task. American Educational Research Journal, 41(2), 365-399. https://doi.org/10.3102/00028312041002365

Demetriou, H., \& Wilson, E. (2009). Synthesising affect and cognition in teaching and learning. Social Psychology of Education, 12, 213-232. https://doi.org/10.1007/s11218-008-9075-X

Dewiyanti, S., Brand-Gruwel, S., Jochems, W., \& Broers, N. J. (2007). Students' experiences with collaborative learning in asynchronous computer-supported collaborative learning environments. Computers in Human Behavior, 23(1), 496-514. https://doi.org/10.1016/j.chb.2004.10.021

DiBiase, W., \& McDonald, J. R. (2015). Science teacher attitudes toward inquiry-based teaching and learning. The Clearing House: A Journal of Educational Strategies, Issues and Ideas, 88(2), 29-38. https:// doi.org/10.1080/00098655.2014.987717

Dillenbourg, P. (2008). Integrating technologies into educational ecosystems. Distance Education, 29(2), 127-140. https://doi.org/10.1080/01587910802154939

Dillenbourg P., \& Jermann P. (2010). Technology for classroom orchestration. In M. Khine \& I. Saleh (Eds.), New science of learning (pp. 525-552). Springer. https://doi.org/10.1007/978-1-4419-5716-0_ 26

Efklides, A. (2017). Affect, epistemic emotions, metacognition, and self-regulated learning. Teachers College Record, 119(13), 1-22.

Engeström-Öst, J., Holmborn, T., Brutemark, A., Hogfors, H., Vehmaa, A., \& Gorokhova, E. (2014). The effects of short-term $\mathrm{pH}$ decrease on the reproductive output of the Copepod Acartia Bifilosa - A laboratory study. Marine and Freshwater Behaviour and Physiology, 47(3), 173-183. https://doi.org/10. 1080/10236244.2014.919096

Ertmer, P. A., \& Ottenbreit-Leftwich, A. T. (2010). Teacher technology change: How knowledge, confidence, beliefs, and culture intersect. Journal of Research on Technology in Education, 42(3), 255-284.

Fauville, G., Säljö, R., \& Dupont, S. (2013). Impact of ocean acidification on marine ecosystems: educational challenges and innovations. Marine Biology, 160, 1863-1874. https://doi.org/10.1007/ s00227-012-1943-4

Feldman Barrett, L., \& Russell, J. A. (1998). Independence and bipolarity in the structure of current affect. Journal of Personality and Social Psychology, 74, 967-984. https://doi.org/10.1080/13504 622.2013 .775220

Frenzel, A. C. (2014). Teacher Emotions. In R. Pekrun \& L. Linnenbrink-Garcia (Eds.). International Handbook of Emotions in Education (pp. 494-519). Routledge.

Frenzel A. C., Goetz T., Stephens E. J., \& Jacob B. (2009). Antecedents and effects of teachers' emotional experiences: An integrated perspective and empirical test. In P. Schutz \& M. Zembylas (Eds.), Advances in teacher emotion research (pp. 129-151). Springer. https://doi.org/10.1007/ 978-1-4419-0564-2_7

Furtak, E. M., Seidel, T., Iverson, H., \& Briggs, D. C. (2012). Experimental and quasi-experimental studies of inquiry-based science teaching: A meta-analysis. Review of Educational Research, 82(3), 300-329. https://doi.org/10.3102/0034654312457206

Greiffenhagen, C. (2012). Making rounds: The routine work of the teacher during collaborative learning with computers. Computer Supported Learning, 7, 11-42. https://doi.org/10.1007/s11412-011-9134-8

Hagenauer, G., Hascher, T., \& Volet, S. E. (2015). Teacher emotions in the classroom: Associations with students' engagement, classroom discipline and the interpersonal teacher-student relationship. European Journal of Psychology of Education, 30, 385-403. https://doi.org/10.1007/ s10212-015-0250-0

Hamre, B. K., Pianta, R. C., Downer, J. T., DeCoster, J., Mashburn, A. J., Jones, S. M., Brown, J. L., Cappella, E., Atkins, M., Rivers, S. E., Brackett, M. A., \& Hamagami, A. (2013). Teaching through interactions: Testing a developmental framework of teacher effectiveness in over 4,000 classrooms. The Elementary School Journal, 113(4), 461-487.

Hascher, T. (2010). Learning and emotion: Perspectives for Theory and Research. European Educational Research Journal, 9(1), 13-28. https://doi.org/10.2304/eerj.2010.9.1.13

Harris, C. J., \& Rooks, D. L. (2010). Managing inquiry-based science: Challenges in enacting complex science instruction in elementary and middle school classrooms. Journal of Science Teacher Education, 21, 227-240. https://doi.org/10.1007/s10972-009-9172-5 
Hijzen, D., Boekaerts, M., \& Vedder, P. (2007). Exploring the links between students' engagement in cooperative learning, their goal preferences and appraisals of instructional conditions in the classroom. Learning and Instruction, 17, 673-687. https://doi.org/10.1016/jlearninstruc.2007.09.020

Hmelo-Silver, C., Duncan, R., \& Chinn, C. (2007). Scaffolding and achievement in problem-based and inquiry learning: A response to Kirschner, Sweller, and Clark (2006). Educational Psychologist, 42, 99-107. https://doi.org/10.1109/TE.2018.2791445

Holzkamp, K. (1991). Societal and individual life processes. In C. W. Tolman \& W. Maiers (Eds.), Critical psychology: Contributions to an historical science of the subject (pp. 50-64). Cambridge University Press.

Howe, C., Tolmie, A., Thurston, A., Topping, K., Christie, D., Livingston, K., Jessiman, E., \& Donaldson, C. (2007). Group work in elementary science: Towards organisational principles for supporting pupil learning. Learning and Instruction, 17(5), 549-563. https://doi.org/10.1016/j.learninstruc.2007.09.004

Hsieh, Y. H., \& Tsai, C. C. (2012). The effect of moderator's facilitative strategies on online synchronous discussions. Computers in Human Behavior, 28, 1708-1716. https://doi.org/10.1016/j.chb. 2012.04.010

Janssen, J., Erkens, G., Kirschner, P. A., \& Kanselaar, G. (2012). Task-related and social regulation during online collaborative learning. Metacognition Learning, 7, 25-43. https://doi.org/10.1007/ s11409-010-9061-5

Jiang, J., Vauras, M., Volet, S., \& Wang, Y. (2016). Teachers' emotions and emotion regulation strategies: Self- and students' perceptions. Teaching and Teacher Education, 54, 22-31. https://doi.org/10.1016/j. tate.2015.11.008

Järvenoja, H., Malmberg, J., Törmänen, T., Mänty, K., Haataja, E., Ahola, S., \& Järvelä, S. (2020). A collaborative learning design for promoting and analyzing adaptive motivation and emotion regulation in the science classroom. Frontiers in Education, 5, 111. https://doi.org/10.3389/feduc.2020.00111

Kim, C., \& Pekrun, R. (2014). Emotions and motivation in learning and performance. In J. M. Spector, M. D. Merrill, J. Elen, \& M. J. Bishop (Eds.), Handbook of research on educational communications and technology (pp 65-75). Springer.

Kirschner, F., Paas, F., Kirschner, P. A., \& Janssen, J. (2011). Differential effects of problem-solving demands on individual and collaborative learning outcomes. Learning and Instruction, 21(4), 587599. https://doi.org/10.1016/j.learninstruc.2011.01.001

Kirschner, P. A., Sweller, J., \& Clark, R. E. (2006). Why minimal guidance during instruction does not work: An analysis of the failure of constructivist, discovery, problem-based, experiential, and inquiry- based teaching. Educational Psychologist, 41, 75-86. https://doi.org/10.1207/s15326985e p4102_1

Klem, A. M., \& Connell, J. P. (2004). Relationships matter: Linking teacher support to student engagement and achievement. Journal of School Health, 74(7), 262-273.

Kreijns, K., Kirschner, P. A., \& Vermeulen, M. (2013). Social aspects of CSCL environments: A research framework. Educational Psychologist, 48(4), 229-242. https://doi.org/10.1080/00461520. 2012.750225

Kwon, K., Liu, Y.-H., \& Johnson, L. P. (2014). Group regulation and social-emotional interactions observed in computer supported collaborative learning: Comparison between good vs. poor collaborators. Computers \& Education, 78, 185-200. https://doi.org/10.1016/j.compedu.2014.06.004

Lederman, J., Lederman, N., Bartels, S., Jimenez, J., Akubo, M., Aly, S., Bao, C., Blanquet, E., Blonder, R., de Andrade, M. B. S., Buntting, C., Cakir, M., EL-Deghaidy, H., ElZorkani, A., Gaigher, E., Guo, S., Hakanen, A., Al- Lal, S. H., Han- Tosunoglu, C., ... Zhou, Q. (2019). An international collaborative investigation of beginning seventh grade students' understandings of scientific inquiry: Establishing a baseline. Journal of Research in Science Teaching, 56(4), 486-515. https://doi.org/ 10.1002/tea.21512.

Linnenbrink-Garcia, L., Rogat, T. K., \& Koskey, K. L. K. (2011). Affect and engagement during small group instruction. Contemporary Educational Psychology, 36, 13-24. https://doi.org/10.1016/j. cedpsych.2010.09.001

Lo, J., \& Tierney, G. (2017). Maintaining interest in politics: 'Engagement first' in a U.S. high school government course. Journal of Social Science Education, 16, 61-72. https://doi.org/10.2390/ jsse-v16-i3-1572

Maeng, J. L., Mulvey, B. K., Smetana, L. K., \& Bell, R. L. (2013). Preservice teachers' TPACK: Using technology to support inquiry instruction. Journal of Science Education and Technology, 22, 838857. https://doi.org/10.1007/s10956-013-9434-z

Malecki, C. K., \& Demaray, M. K. (2003). What type of support do they need? Investigating student adjustment as related to emotional, informational, appraisal, and instrumental support. School Psychology Quarterly, 18(3), 231-252. https://doi.org/10.1521/scpq.18.3.231.22576 
Maria, F., Santos, T., \& Mortimer, E. F. (2003). How emotions shape the relationship between a chemistry teacher and her high school students. International Journal of Science Education, 25(9), 10951110. https://doi.org/10.1080/0950069032000052216

Martin, D. P., \& Rimm-Kaufman, S. E. (2015). Do student self-efficacy and teacher-student interaction quality contribute to emotional and social engagement in fifth grade math? Journal of School Psychology, 53(5), 359-373. https://doi.org/10.1016/j.jsp.2015.07.001

Mazer, J. P., McKenna-Buchanan, T. P., Quinlan, M. M., \& Titsworth, S. (2014). The dark side of emotion in the classroom: Emotional processes as mediators of teacher communication behaviors and student negative emotions. Communication Education, 63(3), 149-168. https://doi.org/10.1080/ 03634523.2014 .904047

Meyer, D. K. (2014). Situating emotions in classroom practices. In R. Pekrun \& L. Linnenbrink- Garcia (Eds.), International handbook of emotions in education (pp. 458-472). Routledge.

McNeill, K. L., Pimentel, D. S., \& Strauss, E. G. (2013). The impact of high school science teachers' beliefs, curricular enactments and experience on student learning during an inquiry-based urban ecology curriculum. International Journal of Science Education, 35(15), 2608-2644. https://doi. org/10.1080/09500693.2011.618193

Mojavezi, A., \& Tamiz, M. P. (2012). The impact of teacher self-efficacy on the students' motivation and achievement. Theory and Practice in Language Studies, 2(3), 483-491. https://doi.org/10.4304/ tpls.2.3.483-491

Nolen, S. B., Wetzstein, L., \& Goodell, A. (2020). Designing Material Tools to Mediate Disciplinary Engagement in Environmental Science. Cognition and Instruction, 38(2), 179-223. https://doi.org/ 10.1080/07370008.2020.1718677

Osborne, J., Simon, S., Christodoulou, A., Howell-Richardson, C., \& Richardson, K. (2013). Learning to argue: A study of four schools and their attempt to develop the use of argumentation as a common instructional practice and its impact on students. Journal of Research in Science Teaching, 50(3), 315-347. https://doi.org/10.1002/tea.21073

Pietarinen, T., Vauras, M., Laakkonen, E., Kinnunen, R., \& Volet, S. (2019). High school students' perceptions of affect and collaboration during virtual science inquiry learning. Journal of Computer Assisted Learning, 35, 334-348. https://doi.org/10.1111/jcal.12334

Pietarinen, T., Volet, S., Lehtinen, E., \& Vauras, M. (2020). Affect in peer group learning during virtual science inquiry: Insights from self-reports and video observations. Frontiers in Psychology, 10, 2981. https://doi.org/10.3389/fpsyg.2019.02981

Ritchie, S. M., Tobin, K., Sandhu, M., Sandhu, S., Henderson, S., \& Roth, W.- M. . (2013). Emotional arousal of beginning physics teachers during extended experimental investigations. Journal of Research in Science Teaching, 50, 137-161. https://doi.org/10.1002/tea.21060

Roth, W.-M. (2007). Emotion at Work: A Contribution to Third-Generation Cultural-Historical Activity Theory. Mind, Culture, and Activity, 14(1-2), 40-63. https://doi.org/10.1080/10749030701307705

Sampson, V., \& Clark, D. (2009). The impact of collaboration on the outcomes of scientific argumentation. Science Education, 93, 448-484.

Scherer, K. R. (2005). What are emotions? And how can they be measured? Social Science Information, 44, 695-729. https://doi.org/10.1177/0539018405058216

Schuman \& Scherer, (2014). Concepts and Structures of Emotions. In R. Pekrun, \& L. Linnenbrink- Garcia (Eds.), International handbook of emotions in education (pp. 13-35). New York/London: Routledge.

Sinha, S., Rogat, T. K., Adams-Wiggins, K. R., \& Hmelo-Silver, C. E. (2015). Collaborative group engagement in a computer-supported inquiry learning environment. International Journal of Computer-Supported Collaborative Learning, 10, 273-307. https://doi.org/10.1007/s11412-015-9218-y

Slakmon, B., \& Schwartz, B. B. (2019). Deliberative emotional talk. International Journal of ComputerSupported Collaborative Learning, 14, 185-217. https://doi.org/10.1007/s11412-019-09304-3

Solanas, A., Selvam, R. M., Navarro, J., \& Leiva, D. (2012). Some common indices of group diversity: Upper boundaries. Psychological Reports, 111(3), 777-796.

Song, Y., \& Looi, C. (2012). Linking teacher beliefs, practices and student inquiry-based learning in a CSCL environment: A tale of two teachers. Computer Supported Learning, 7, 129-159. https://doi.org/ 10.1007/s11412-011-9133-9

Spronken-Smith, R., \& Walker, R. (2010). Can inquiry- based learning strengthen the links between teaching and disciplinary research? Studies in Higher Education, 35(6), 723-740. https://doi.org/10.1080/ 03075070903315502

Summers, M., \& Volet, S. (2010). Group work does not necessarily equal collaborative learning: Evidence from observations and self-reports. European Journal of Psychology of Education, 25, 473-492. https://doi.org/10.1007/s10212-010-0026-5 
Tardy, C. H. (1985). Social support measurement. American Journal of Community Psychology, 13, 187202. https://doi.org/10.1007/BF00905728

Telenius, M., Yli-Panula, E., Vesterinen, V.-M., \& Vauras, M. (2020). Argumentation within upper secondary school student groups during virtual science learning: Quality and quantity of spoken argumentation. Educational Sciences, 10(12), 393. https://doi.org/10.3390/educsci10120393

Tennant, J. E., Demaray, M. K., Malecki, C. K., Terry, M. N., Clary, M., \& Elzinga, N. (2014). Students' ratings of teacher support and academic and social- emotional well-being. School Psychology Quarterly. Advance online publication. https://doi.org/10.1037/spq0000106

Tondeur, J., van Braak, J., Ertmer, P. A., \& Ottenbreit-Leftwich, A. (2017). Understanding the relationship between teachers' pedagogical beliefs and technology use in education: A systematic review of qualitative evidence. Educational Technology Research and Development, 65(3), 555-575. https://doi.org/10. 1007/s11423-016-9481-2

Trigwell, K. (2012). Relations between teachers' emotions in teaching and their approaches to teaching in higher education. Instructional Science, 40, 607-621. https://doi.org/10.1007/s11251-011-9192-3

Tseng, C., Tuan, H., \& Chin, C. (2013). How to help teachers develop inquiry teaching: Perspectives from experienced science teachers. Research in Science Education, 43, 809-825. https://doi.org/10.1007/ s11165-012-9292-3

Turner, J. C., \& Meyer, D. K. (2000). Studying and understanding the instructional contexts of classrooms: Using our past to forge our future. Educational Psychologist, 35(2), 69-85. https://doi.org/10.1207/ S15326985EP3502_2

Tytler, R., \& Aranda, G. (2015). Expert teachers' discursive moves in science classroom interactive talk. International Journal of Science and Mathematics Education, 13, 425-446. https://doi.org/10.1007/ s10763-015-9617-6

Van Leeuwen, A., Janssen, J., Erkens, G., \& Brekelmans, M. (2013). Teacher interventions in a synchronous, co-located CSCL setting: Analyzing focus, means, and temporality. Computers in Human Behavior, 29(4), 1377-1386. https://doi.org/10.1016/j.chb.2013.01.028

Van Leeuwen, A., \& Rummel, N. (2019). Orchestration tools to support the teacher during student collaboration: a review. Unterrichtswiss, 47, 143-158. https://doi.org/10.1007/s42010-019-00052-9

Vauras, M., Volet, S., \& Nolen, S. (2019). Supporting motivation in collaborative learning: Challenges in the face of an uncertain future. In E. Gonida \& M. Lemos (Eds.), Motivation in education at a time of global change: Theory, research, and implications for practice. Emerald.

Volet, S., Vauras, M., Khosa, D., \& Iiskala, T. (2013). Metacognitive regulation in collaborative learning: Conceptual developments and methodological contextualizations. In S. Volet \& M. Vauras (Eds.), Interpersonal regulation of learning and motivation: Methodological advances (pp. 67-101). Routledge.

Webb, N. M., Franke, M. L., Marsha, M., Turrou, A. C., Johnson, N. C., \& Zimmerman, J. (2019). Teacher practices that promote productive dialogue and learning in mathematics classrooms. International Journal of Educational Research, 97, 176-186. https://doi.org/10.1016/j.ijer.2017.07.009

Windschitl, M. (2003). Inquiry projects in science teacher education: What can investigative experiences reveal about teacher thinking and eventual classroom practice? Science Education, 87(1), 112-143. https://doi.org/10.1002/sce.10044

Zembylas, M. (2002). Constructing genealogies of teachers' emotions in science teaching. Journal of Research in Science Teaching, 39, 79-103. https://doi.org/10.1002/tea.10010

Zhang, T., Solmon, M. A., \& Gu, X. (2012). The role of teachers' support in predicting students' motivation and achievement outcomes in physical education. Journal of Teaching in Physical Education, 31, 329-343. https://doi.org/10.1123/jtpe.31.4.329

Publisher's note Springer Nature remains neutral with regard to jurisdictional claims in published maps and institutional affiliations. 